15. Лабунский В.В. Методические рекомендации по физическому воспитанию учащихся, отнесенных к специальной медицинской группе. Тбилиси, 1985. 18 с.

16. Рожков П.А. Развитие физической культуры и спорта - приоритетное направление социальной политики государства // Теория и практика физической культуры. 2012. № 1. С. 2-7.

17. Примерная программа по дисциплине «Физическая культура» (Квалификации (степени) выпускника бакалавр). Министерство образования и науки Российской Федерации.

18. Трудовой кодекс Российской Федерации от 30.12.2001 N 197-Ф3 (ред. от 23.07.2013, с изм. и доп., вступающими в силу с 01.09.2013) // Российская газета, № 256, 31.12.2001.

19. Земсков А.С., Иванчин А.И. Разработка и внедрение компьютерных программ в деятельность учителя физической культуры - проблемы и перспективы // Азимут научных исследований: педагогика и психология. 2015. № 3 (12). С. 13-18.

20. Бакулина Я.С., Ведерников А.В., Гусев А.А. Социально-экономические проблемы в области спорта и физической культуры системы вуза, пути решения и развития // Вестник НГИЭИ. 2015. № 9 (52). С. 18-22.

21. Восколович Н.А., Кугоев И.А. Актуальные аспекты менеджмента в сфере гольфа: управление взаимодействием потребителей услуг и гольф-клубов // Азимут научных исследований: экономика и управление. 2015. № 4 (13). С. 28-31.

22. Федулов И.С., Медведева И.А. Влияние занятий спортом на социально психологические характеристики подростков // XXI век: итоги прошлого и проблемы настоящего плюс. 2014. № 4. С. 183-187.

23. Jihad D.M. Ways of development of militaryphysical training in azerbaijan during the period of independence // Азимут научных исследований: педагогика и психология. 2015. № 4 (13). С. 38-39.

24. Теория и организация адаптивной физической культуры. Т. 2: Учебник в 2 т. / под общ. ред. проф. С.П. Евсеева. М.: Педагогическое общество России, 2011. $448 \mathrm{c}$

25. Щетинин M.Н. Дыхательная гимнастика А.Н. Стрельниковой. М.: Метафора, 2007. 128 с.

\title{
MODEL OF LABOUR SAFETY AND HEALTH PROTECTION OF COLLEGE STUDENTS FROM A SPECIAL MEDICAL GROUP
}

(C) 2016

G.M. Il'mushkin, EdD, professor, professor of the Chair of Higher Mathematics O.V. Parhaeva, head of the Chair of Physical Culture and Sport, postgraduate student Y.E. Sudakova, $\mathrm{PhD}$, associate professor of the Chair of Physical Culture and Sport Dimitrovgrad Engineering-Technical Institute branch of National Nuclear Research University MEPhI, Dimitrovgrad (Russia)

Abstract. This paper presents an overview of the state of health of students at the present stage of development of education in the Russian Federation, factors are justified which determine the progress of a number of resistant diseases associated with conditions of mental work at the university. On the basis of the facts available and analysis of medical and educational documentation of Dimitrovgrad Engineering-Technical Institute - branch of National Nuclear Research University MEPhI (Diti MEPhI) the paper shows the dynamics of the number of students assigned to a special medical group (SMG), as well as morbidity structure of the nosological status. This group of students have special needs as far as their physical training is concerned. In this regard, the authors suggest the optimal structuring of the content of physical education for the SMG students which is based on their physical health, psycho-emotional characteristics, motivation and attitude to physical self-improvement, as well as the introduction of competence-based approach in physical training class. At the same time physical education is considered in the context of labour safety and health protection. Thus, the authors propose a model of health protection of SMG students. In the model developed, considerable attention is given to improving the students' physical education by introducing innovative pedagogical tools of communication in the educational process.

Keywords: educational activity, physical education, health, labor protection, a special medical group, value, attitude, competence approach.

УДК 371.123

\section{СТРУКТУРА АНАЛИТИЧЕСКОЙ ДЕЯТЕЛЬНОСТИ РУКОВОДИТЕЛЯ ОБЩЕОБРАЗОВАТЕЛЬНОЙ ОРГАНИЗАЦИИ}

(C) 2016

Н.Н. Коваль, методист

Донеикий республиканский институт дополнительного педагогического образования, Донеик (Донеикая Народная Республика)

\footnotetext{
Аннотащия. В статье рассмотрены сложившиеся в педагогике подходы к структурированию и описанию компонентов аналитической деятельности. Представлены различные модели аналитической деятельности: деятельностный подход (Е.В. Назначило, Н.А. Зинчук, В.В. Ягупов, Н.П. Пичугова), системный подход (Л.П. Половенко, О.Н. Ярыгин, А.А. Коростелев), структурно-деятельностный подход (Л.М. Плахова). Охарактеризованы основные компоненты и этапы аналитической деятельности в зависимости от представленного подхода. Акцент сделан на трехмерной модели аналитической деятельности руководителя общеобразовательной организации: технология
} 
Коваль Н.Н.

анализа результатов работы образовательной системы (автор А.А. Коростелев), элементом которой является эвристический алгоритм нематематического характера, состоящий из пяти этапов. Данная технология объединила в себе мотивационно-смысловой, целевой, технологический уровни. Выделены и описаны структурные компоненты аналитической деятельности руководителя школы: ценностно-мотивационный (личностное отношение руководителя к аналитической деятельности, ценность сторон и ее значимость в управленческой деятельности, потребность личности совершенствоваться и развиваться в этом виде деятельности), целевой (интенциональный аспект), когнитивно-операционный (комплекс знаний, умений, практических навыков, необходимый для осуществления эффективной и результативной аналитической деятельности), рефлексивный (самооценка, самоанализ, самоуправление, самопроектирование собственной аналитической деятельности).

Ключевые слова: анализ, деятельность, аналитическая деятельность, аналитическая деятельность руководителя общеобразовательной организации, структура аналитической деятельности, этапы аналитической деятельности, деятельностный подход, системный подход.

Постановка проблемы в общем виде и ее связь с важными научными и практическими задачами. Аналитические знания, с одной стороны, представляют собой эффективный инструмент, который многократно увеличивает возможности руководителя общеобразовательной организации и позволяет достигать лучших результатов в управленческой деятельности. С другой стороны, игнорирование, незнание, нарушение законов управления приводит к отрицательным результатам и негативным последствиям. Современная школа нуждается в знающих менеджерах и умелых аналитиках, способных к постоянному развитию аналитического и рефлексивного мышления, интеллектуальных способностей, креативности, к осуществлению самооценки и самоанализа своей управленческой деятельности, мотивированных к самосовершенствованию и развитию себя как личности.

В условиях изменений, происходящих в образовании, необходимо обеспечить повышение аналитического уровня профессиональной деятельности руководителей школ, что во многом определит эффективность управления процессами функционирования и развития общеобразовательной организации. Также высокий аналитический уровень профессиональной деятельности руководителя обеспечивает гуманистическое и демократическое управление, что позволяет формировать позитивные мотивы у педагогов и обучающихся.

Несомненно, «Переход к новому подходу к управлению - аналитическому - обусловливает необходимость переосмысления многих положений аналитической деятельности и необходимости ее технологизации.» $[1$, с. 9], а также выявление и обоснование структурных компонентов аналитической деятельности руководителя школы, критериев сформированности аналитической компетентности.

Анализ последних исследований и публикаџий, в которых рассматривались аспекты этой проблемы и на которых основывается автор; выделение неразрешенных раньше частей общей проблемы. В.В. Дудников, Ю.А. Конаржевский, В.С. Лазарев, А.М. Моисеев, М.Л. Портнов, М.М. Поташник, Н.В. Рогожкина, В.К. Терентьев, Л.И. Фишман, Т.И. Шамова, В.Н. Чупин осуществляли исследование вопросов менеджмента и качества управления школой.

В работах В.И. Бондаря, Б. Канаева, В.М. Кожухар, Ю.А. Конаржевского, А.А. Коростелева, К.Л. Крутий, Г.О. Савченко, В.А. Сластенина, В.Д. Федорова, Г.В. Федорова, В.В. Ягупова, О.Н. Ярыгина сделан акцент на значении аналитической деятельности в управлении учебным заведением.

Раскрыли методику формирования аналитической компетентности в своих диссертационных исследова- ниях И.А. Абрамова, Н.А. Зинчук, А.А. Коростелев, Е.В. Назначило, Н.П. Пичугова, Л.П. Половенко, В.В. Ягупов, О.Н. Ярыгин.

Формирование изелей статьи (постановка задания). Рассмотреть сложившиеся в педагогике подходы к структурированию и описанию компонентов аналитической деятельности. Представить различные модели аналитической деятельности с описанием основных ее компонентов и этапов. Выделить и описать структурные компоненты аналитической деятельности руководителя общеобразовательной организации.

Изложение основного материала исследования с полным обоснованием полученных научных результатов. Рассмотрим сложившиеся в педагогике подходы к структурированию и описанию компонентов аналитической деятельности.

Так, Е.В. Назначило [2], исследуя развитие информационно-аналитической компетентности преподавателя в процессе непрерывного педагогического образования, определяет информационно-аналитическую деятельность преподавателя как вид профессиональной деятельности, представляющий собой целенаправленный поиск, сбор, качественно-содержательное преобразование (анализ и обработка) информации и продуктивное ее использование для решения профессиональных задач. Автор выделяет четыре этапа информационно-аналитической деятельности: мотивационноцелевой, исполнительный, результативный, оценочный. Структурно данный вид деятельности представлен как целостное единство когнитивного, операционного $u$ рефлексивного компонентов. Система теоретических и технологических информационно-аналитических знаний образует когнитивныци компонент; система информационно-аналитических умений, построенная в соответствии с этапами информационно-аналитической деятельности, представляет собой операционный компонент; рефлексивный компонент осуществляет регулирование информационно-аналитической деятельности преподавателя с помощью механизмов самооценки, самоанализа, самопроектирования и самоуправления.

С точки зрения Н.А. Зинчук [3], аналитическая компетентность будущего менеджера является составляющей профессиональной компетентности и представляет собой интегративную динамическую, постоянно обогащающуюся характеристику студентаменеджера, и обусловливает в будущем способность к выполнению им профессиональных аналитических задач в сфере управления. Обеспечивают процесс формирования аналитической компетентности будущего менеджера пять этапов: подготовительный, мотивациионный, когнитивный, действенно-практический, оценочно-результативный. Исследователь описывает 
структуру аналитической компетентности, состоящей из таких компонентов:

- цуенностно-мотивационный, связанный с осознанием ценностных сторон аналитической деятельности, значимости аналитической компетентности в управленческой деятельности, отношением к учебе, желанием личности совершенствоваться и развиваться в этом виде деятельности;

- когнитивно-операционный, включающий в себя сформированность знаний, умений, навыков по аналитической деятельности, развитие аналитического мышления, первичный профессиональный опыт по аналитике, творческая активность;

- рефлексивно-оченочнылй, обеспечивающий самооценку собственной аналитической компетентности, стремление к дальнейшему ее совершенствованию, способность к рефлексии собственного опыта.

Данный подход к структурированию аналитической деятельности отличается от представленного выше наличием ценностно-мотивационного компонента, что является существенным отличием, а сам компонент важным, так как переоценить значение мотивации в любой деятельности невозможно.

B.B. Ягупов [4] предлагает понимать аналитическую деятельность руководителя профессиональнотехнического учебного заведения (ПТУ) как способность и готовность успешно решать различные аналитические задачи научного, исследовательского, управленческого, педагогического, хозяйственного и другого направления, которые обеспечивают эффективность конструирования и программирования практического решения управленческих проблем в ПТУ. Аналитическая деятельность является интегральной составляющей информационно-аналитической компетентности руководителя ПТУ, а также важной составляющей управленческой компетентности. В.В. Ягупов выделяет такие компоненты информационно-аналитической компетентности руководителя ПТУ:

- изенностно-мотивационныли, характеризующий мотивационное и личностное отношение к информации и управленческой деятельности как субъекта управления;

- когнитивнылй, означающий наличие у руководителя системы информационно-аналитических знаний и сформированность системы практических знаний по осуществлению аналитической деятельности по применению информации в своей управленческой деятельности;

- поведенческо-деятельностный, определяющий уровень информационной и компьютерной культуры субъекта управления, уровень аналитического мышления, степень развития интеллектуальных способностей, способность разрешения управленческих проблемных ситуаций в ПТУ;

- коммуникативный, предполагающий способность придерживаться принципов и правил поведения при совместной деятельности в информационной среде и коммуникативных системах «человек-человек»;

- субъектный или рефлексивный и саморефлексивнылй, включающий в себя осмысление, самоанализ, саморефлексию, самооценку и саморегуляцию руководителем ПТУ собственной управленческой деятельности и ее результатов.

Описанная выше структура информационно-аналитической компетентности дополнительно включает в себя коммуникативный компонент. Очевидно, это связано с тем, что в данном случае аналитическая деятельность не рассматривается в чистом виде, а как интегральная ее составляющая.

Согласно Н.П. Пичуговой [5], аналитическая деятельность субъектов образования педагогчческого колледжа является одним из компонентов педагогической деятельности и элементом процесса управления с одной стороны, и фактором, влияющим на качество результата этого процесса с другой стороны. Как отмечает автор, аналитическая деятельность разных субъектов образовательного процесса педагогического колледжа имеет отличия, связанные с разной их содержательной направленностью. Так, у администрации колледжа аналитическая деятельность имеет управленческую ориентацию, у преподавателей - методическую ориентацию и, наконец, у студентов аналитическая деятельность носит образовательный характер. Но, вне зависимости от содержательной направленности субъектов образования, аналитическая деятельность имеет одни и те же структурные компоненты: мотив, определяющий общую направленность деятельности; иель, определяющая преднамеренный характер действий; операции, которые непосредственно зависят от условий достижения конкретной цели. Безусловно, что в основу модели аналитической деятельности положена теория деятельности, разработанная А.Н. Леонтьевьм [6].

Л.П. Половенко [7] в своих работах рассматривает аналитическую компетентность будущуих специалистов по экономической кибернетике как ключевую составляющую профессиональной компетентности. По мнению автора, аналитическая компетентность означает способность к аналитическому мылилению и наличие аналитических способностей, умение проводить мониторинг деятельности предприятия, собственной деятельности и основных конкурентов на рынке, планировать материальные и трудовые затраты, проводить диагностику производственно-экономического потенциала предприятия, определять тенденции его развития, умение осуществлять анализ по следующим направлениям: эффективность работы предприятия, потребность в ресурсах, эффективность связей, производительность труда, эффективность стратегии управления, финансово-хозяйственная деятельность предприятия.

Основными составляющими аналитической компетентности специалиста по экономической кибернетике (Л.П. Половенко) являются следующие компетенции: информационно-аналитическая, учетно-аналитическая, финансово-аналитическая, математическая или количественно-аналитическая, системно-аналитическая, ITаналитическая. Перечисленные компетенции формируются диффузно, взаимопроникая и взаимно дополняя друг друга. Результатом такой интеграции указанных компетенций становится целостная аналитическая компетентность, что в конечном итоге приводит к синергетическому эффекту. Л.П. Половенко воспользовался системным подходом к исследованию аналитической компетентности.

О.Н. Ярыгин [8] в своем диссертационном исследовании «Формирование компетентности аналитической деятельности в подготовке научных и научнопедагогических кадров высшей школы» на основе системного подхода описывает девять этапов аналити- 
Коваль Н.Н.

ческой деятельности как деенаправленного анализасинтеза:

1) выделение реального объекта из окружающей среды с целью выявления взаимодействия системы с внешней средой, и таким образом определяются свойства системы, подлежащие рассмотрению и пониманию. Структурная модель «черный ящик» является результатом первого этапа;

2) выделение элементов системы, в предположении их взаимодействия, для обеспечения выявленных на предыдущем этапе свойств системы. Выявленные элементы считаются «неделимыми» (атомами), нерасчленимыми. На этом этапе возникают понятия целого и части, из которых происходят свойства целого (то есть результата взаимодействия его частей) и свойства частей в общем виде;

3) установление взаимодействий выявленных элементов системы. При анализе-синтезе определяется логическая структура системы. Результатом данного этапа аналитической деятельности является установление логической структуры взаимодействия системы как единства выявленных элементов, внутренних взаимодействий и взаимодействий с универсумом (аналитикосинтетическая задача аналитической деятельности);

4) выявление причин эмерджентных свойств системы. И это возникшее (эмерджентное) свойство требуется осознать в рамках рассматриваемой системы, но с привлечением новых понятий. Таковыми будут выявляемые подсистемы. Именно взаимодействие подсистем, а не элементов порождает эмерджентные свойства;

5) определение функций элементов и подсистем в выявленной логической структуре системы. Данный этап называется функциональным моделированием рассматриваемой системы;

6) определение цели системы в терминах выявленных функций элементов и подсистем. Для этого потребуется соотнесение состояний системы и внешней среды;

7) выявление переменных системы и параметров, которые поддаются только наблюдению, но не целенаправленному изменению. В результате анализа и синтеза совокупности воздействий на исследуемую систему и её целей возникает задача управления системой, которая состоит в целенаправленном изменении переменных системы для приведения её в одно из терминальных состояний;

8) выявление «петель обратных связей», что позволяет определить динамические закономерности функционирования системы. На этом этапе анализ и синтез неразделимы;

9) определение управляющих воздействий, то есть структурное и количественное определение воздействий на систему с целью приведения системы в заданное состояние.

Интересным аспектом данной научной работы является то, что автор предлагает для аналитической деятельности не выделять какую-то специфическую «аналитическую компетентность», так как это противоречит такому свойству компетентности как переносимость на другие области деятельности. О.Н. Ярыгин считает, что таким видом компетентности для аналитической деятельности является интеллектуальная компетентность, представляющая собой единство языко- вой, дедуктивной, индуктивной и алгоритмической компетентностей (компетентностный подход). С другой стороны, интеллектуальная компетентность есть единство компонентов, обладающее сложной структурой: интеллект, креативность, мотивация достижений, рефлексия (структурно-системный подход). Таким образом, аналитическая деятельность - это процесс взаимодействия интеллектуальных способностей, креативности, рефлексии и мотивации, обеспечивающий возможность принятия эффективных решений в определённой области деятельности.

При описании структурных компонентов аналитической деятельности руководителя образовательного учреждения Л.М. Плахова воспользовалась структурно-деятельностным подходом [9, с. 11] и считает, что любая деятельность состоит из четырех уровней:

- мотивационно-смысловой уровень, раскрывающий понятия общей направленности деятельности;

- интенциональный (целевой) уровень, определяющий цели как образа того, что должно быть достигнуто;

- технологический (операционный) уровень, предполагающий выбор наиболее эффективных технологий осуществления действий для конкретной общеобразовательной организации и конкретной управленческой ситуации;

- ресурсный уровень, характеризующий ресурсные возможности образовательного учреждения для осуществления деятельности.

Согласно представленной схеме, аналитическая деятельность направлена на: выявление проблем, постановку задач, решение задач [9, с. 20]. На интенциональном (целевом) уровне автор определяет следующие цели аналитической деятельности:

1. Установление расхождения между требуемым и достигнутым, планируемым и осуществленным и т.д.

2. Формулирование проблем как несоответствие между тем, что должно быть, и тем, что есть.

3. Выявленные причины возникновения проблем определить как недостаток.

4. Структурирование и ранжирование выявленных проблем.

5. Определение цели как образа того, что намерены достичь.

6. Представление условий, необходимых для реализации этих целей.

7. Осуществление отбора основных действий, которые обеспечат достижение цели.

8. Определение ресурсов, необходимых для реализации действий.

9. Установление критериев и параметров, по которым будет оцениваться достижение цели.

Далее Л.М. Плахова предлагает использовать следующие технологии для осуществления анализа: проблемно-ориентированного анализа, целеполагания (дерево целей), ориентировочной основы действий.

С точки зрения Ю.П. Сурмина [10, с. 254], существующие технологии осуществления аналитической деятельности отличаются значительным многообразием и неповторимостью, но вместе с тем они имеют и общие блоки операций, поэтому можно представить универсальную схему технологии анализа:

1. Определение объекта, предмета и проблемы анализа. 
2. Построение идеальной модели объекта и предмета, что обеспечивает создание нормативной базы для последующей исследовательской деятельности.

3. Построение гипотез, позволяющих понять проблему.

4. Выбор типа анализа, который определяется объектом аналитической деятельности.

5. Выбор или разработка методов анализа, предопределяемых типом анализа.

6. Доказательство гипотез на основе выбранного метода.

7. Формулировка аналитических выводов.

A.A. Коростелев $[1,11-16]$ предлагает к использованию трехмерную модель аналитической деятельности руководителя общеобразовательной организащии (анализ осуществляется по горизонтали $\mathbf{X}$, по вертикали $\mathbf{Y}$ и по глубине $\mathbf{Z}$ ), где:

$\mathbf{X}$ - подсистемы образовательного процесса или блоки (базовое образование, дополнительное образование, кадровое обеспечение и т.д.), для которых ставится цель анализа;

$\mathbf{Y}$ - структурные единицы и элементы подсистемы (ступень обучения, параллель, класс и т.д.);

$\mathbf{Z}$ - алгоритм осуществления анализа, представленный в табличной форме.

Эвристический алгоритм проведения анализа результатов работы образовательной системы (ось Z) носит нематематический характер и состоит из пяти этапов:

1 этап. Сравнение фактических и прогнозируемых результатов, что позволяет определить и увидеть расхождения между ними и на основе анализа выявить основные противоречия.

2 этап. Выявленные противоречия.

3 этап. Возможные причины противоречий.

4 этап. Возможные пути решения противоречий.

5 этап. Целевые задачи на следующий учебный год (для целевых блоков - цель направлена на обучаемого) и задачи деятельности на следующий учебный год (для деятельностных блоков - задача направлена не на обучаемого).

Данная технология получила название: технология анализа результатов работы образовательной системы (TAPPOC) «Landrail». Она позволяет осуществлять не только анализ результатов работы образовательной системы от учителя до директора и осуществлять постановку целей и задач образовательного заведения, но и формировать план работы, определять направления контроля в школе. Данная технология гармонично объединила в себе уровни, описанные Л.М. Плаховой: мотивационно-смысловой, целевой, технологический.

Считаем, что данная трехмерная модель аналитической деятельности руководителя общеобразовательной организации является эффективной и перспективной для дальнейшего практического использования школами $[18,19,20]$.

Мы выделяем такие структурные компоненты аналитической деятельности руководителя школы:

- ценностно-мотивационный - личностное отношение руководителя к аналитической деятельности, осознание ее ценностных сторон и значимости в управленческой деятельности, потребность личности совершенствоваться и развиваться в этом виде деятельности;

- целевой - интенциональный аспект, то есть что должно быть достигнуто руководителем школы в про- цессе аналитической деятельности. Важными сторонами процесса целеобразования являются следующие моменты: цели не изобретаются, не ставятся субъектом произвольно, они даны в объективных обстоятельствах; цель должна быть конкретизирована, то есть необходимо выделение условий ее достижения [6];

- когнитивно-операиионный - комплекс знаний, умений, практических навыков, необходимый для осуществления эффективной и результативной аналитической деятельности, владение технологиями осуществления аналитической деятельности, развитие аналитического мышления и интеллектуальных способностей, профессиональный опыт по аналитике, творческая активность, креативность;

- рефлексивный - самооценка, самоанализ, самоуправление, самопроектирование собственной аналитической деятельности, стремление к формированию рефлексивного мышления, саморазвитие личностных качеств и способностей к креативным проявлениям.

Перспективой дальнейшего исследования является выявление критериев сформированности аналитической компоненты управленческой деятельности руководителей общеобразовательных организаций [21-28], а также обоснование структурных компонентов аналитической деятельности.

Выводы исследования и перспективы дальнейших исследований по этому направлению. Целым рядом ученых были выделены структурные компоненты аналитической деятельности. Модели аналитической деятельности различны. А именно:

- согласно Е.В. Назначило, аналитическая деятельность представлена как целостное единство когнитивного, операционного и рефлексивного компонентов;

- согласно Н.А. Зинчук, структура аналитической компетентности состоит из таких компонентов: ценностно-мотивационный, когнитивно-операционный, рефлексивно-оценочный;

- согласно В.В. Ягупову, составляющими информационно-аналитической компетентности будут: ценностно-мотивационный, когнитивный, поведенческодеятельностный, коммуникативный, рефлексивный компоненты;

- согласно Н.П. Пичуговой, деятельностная модель аналитической компоненты педагогической деятельности состоит из таких обязательных элементов: мотив, цель, операции;

- согласно Л.П. Половенко, основными составляющими аналитической компетентности являются следующие компетенции: информационно-аналитическая, учетно-аналитическая, финансово-аналитическая, математическая или количественно-аналитическая, системно-аналитическая, IT-аналитическая;

- согласно О.Н. Ярыгину, аналитическая деятельность - это процесс взаимодействия интеллектуальных способностей, креативности, рефлексии и мотивации, обеспечивающий возможность принятия эффективных решений в определённой области деятельности;

- согласно Л.М. Плаховой, аналитическая деятельность состоит из четырех уровней: мотивационносмысловой, интенциональный (целевой), технологический (операционный), ресурсный;

- согласно А.А. Коростелеву, аналитическая деятельность осуществляется по горизонтали $\mathbf{X}$, по вертикали $\mathbf{Y}$ и по глубине $\mathbf{Z}$ (трехмерная модель), где: $\mathbf{X}-$ подсистемы образовательного процесса или блоки, $\mathbf{Y}-$ 
Коваль Н.Н.

структурные единицы и элементы подсистемы, $\mathbf{Z}$ - алгоритм осуществления анализа, состоящий из пяти этапов.

Считаем, что аналитическая деятельность руководителя общеобразовательной организации содержит такие структурные компоненты: ценностно-мотивационный, целевой, когнитивно-операционный, рефлексивный.

\section{СПИСОК ЛИТЕРАТУРЫ:}

1. Коростелев А.А., Пудовкина Н.Г., Ярыгин О.Н. Аналитическая компетентность и уровни реализации аналитической функции управления: монография. Тольятти: ТГУ, 2011. 287 с.

2. Назначило Е.В. Развитие информационно-аналитической компетентности преподавателя в процессе непрерывного педагогического образования : дис. ... канд. пед. наук : 13.00.08. Магнитогорск, 2003. 193 с.

3. Зінчук Н.А. Формування аналітичної компетентності майбутніх менеджерів у вищих навчальних закладах: дис. ... канд. пед. наук : 13.00.04. Київ, 2010. $219 \mathrm{c}$.

4. Ягупов В.В. Інформаційно-аналітична компетентність керівників професійно-технічних навчальних закладів: поняття, зміст і структура. Режим доступа: http://lib.iitta.gov.ua/7875/1/Статья_нформ.-анал комп1. готоводоc.pdf.

5. Пичугова Н.П. Аналитическая деятельность субъектов образования как средство управления качеством профессиональной подготовки будущих учителей в педагогическом колледже: автореф. дис. ... канд. пед. наук: 13.00.08 / Магнитогорский государственный университет. Магнитогорск, 2009. 23 с.

6. Леонтьев А.Н. Деятельность. Сознание. Личность. М.: Политиздат, 1972. 304 с.

7. Половенко Л.П. Аналітична компетентність ключовий складник професійної компетентності майбутніх фахівців з економічної кібернетики // Научные журналы НТУ «ХПИ»: Теория и практика управления социальными системами. 2012. № 1. С. 82-91

8. Ярыгин О.Н. Методология формирования компетентности в аналитической деятельности при подготовке научных и научно-педагогических кадров: диссертация доктора педагогических наук: 13.00.08 / Ярыгин Олег Николаевич; [Место защиты: ГОУВПО «Тольяттинский государственный университет»]. Тольятти, 2012. 494 с.

9. Плахова Л.М., Решетников Н.Н., Шимутина Е.Н. Организация труда руководителя образовательного учреждения: Учебно-метод. комплект материалов для подготовки тьюторов. М.: АПК и ППРО, 2007. 64 с.

10. Сурмин Ю.П. Теория систем и системный анализ: учеб. пособие. К.: МАУП, 2003. 368 с.

11. Коростелев А.А. Аналитическая деятельность управления: теоретический аспект // Вектор науки Тольяттинского государственного университета. Серия: Экономика и управление. 2012. № 2. С. 35-39.

12. Коростелев А.А. Теоретический аспект ролевого значения аналитической деятельности руководителей образовательных учреждений во внутришкольном управлении // Вестник психотерапии. 2007. Т. 29. № 24. C. $96-100$.

13. Коростелев А.А. Порядок осуществления аналитической деятельности внутришкольного управления // Вектор науки Вектор науки Тольяттинского государственного университета. Серия: Педагогика, психология. 2011. № 1. С. 88-92.
14. Коростелев А.А. Определение уровней и качества аналитической деятельности управления на основе технологии анализа результатов работы образовательной системы (ТАРРОС) // Вектор науки Тольяттинского государственного университета. Серия: Педагогика, психология. 2011. № 4. С. 153-155.

15. Коростелев А.А., Я Ярыгин А.Н., Ярыгина Н.А. Влияние системы повышения квалификации на развитие ключевых компетенций специалистов // Вісник Черкаського Університету. Серія: Педагогічні науки. 2009. № 163. С. 20-26.

16. Коростелев А.А., Деобальд Н.В. Стратиграфическое построение информационного обеспечения аналитической деятельности внутришкольного управления // Сборник научных трудов Sworld по материалам международной научно-практической конференции. 2009. T. 14. № 2. С. 66-69.

17. Коростелев А.А. Стратиграфия уровней управления в социальных и образовательных системах // Вектор науки Вектор науки Тольяттинского государственного университета. Серия: Педагогика, психология. 2010. № 3. С. 75-78.

18. Ярыгин О.Н., Коростелев А.А. Системная динамика как основа современной управленческой компетентности // Актуальные проблемы экономики и права. 2014. № 4 (32). С. 196-205.

19. Коновалова Е.Ю. Особенности лексического использования табличной формализации в аналитической деятельности // Вестник Бурятского государственного университета. 2013. № 1. С. 103-106.

20. Коростелев А.А. Современные подходы к моделированию технологии аналитической деятельности // Вектор науки Тольяттинского государственного университета. 2013. № 1 (23). С. 334-337.

21. Донина И.А. Информационно-аналитический компонент маркетинговой компетентности руководителей образовательных организаций // Балтийский гуманитарный журнал. 2014. № 1. С. 48-50.

22. Коваль Н.Н. Аналитическая деятельность: «пирамида целей» на основе ТАРPOC «Landrail» // Карельский научный журнал. 2014. № 2. С. 38-42.

23. Родионов А.В. Аналитическое исследование процессов функционирования региональных систем высшего образования в Украине // Балтийский гуманитарный журнал. 2014. № 3. С. 83-86.

24. Капустин Н.А. Комплексная автоматизация учетных и аналитических процедур на предприятиях на основе применения современных информационных технологий // Вестник НГИЭИ. 2015. № 7 (50). С. 30-34.

25. Коростелев А.А., Комар Т.В. Управление информационными потоками в аналитической деятельности // Азимут научных исследований: экономика и управление. 2012. № 1. С. 42-45

26. Коваль Н.Н. Аналитическая деятельность: планирование на основе TAPPOC «Landrail» // Балтийский гуманитарный журнал. 2014. № 4. С. 73-77.

27. Коростелев А.А., Полторецкий Д.А. Автоматизированные информационно-аналитические системы в аналитической деятельности управления // Азимут научных исследований: педагогика и психология. 2012. № 1. С. 38-41.

28. Коваль Н.Н. Современные информационно-коммуникационные технологии в аналитической управленческой деятельности: проблемы и перспективы // Карельский научный журнал. 2015. № 1 (10). С. 39-44. 


\section{STRUCTURE OF THE ANALYTICAL ACTIVITY OF THE HEAD OF SCHOOL}

(C) 2016

N.N. Koval, methodist

Donetsk Republican Institute of Additional Pedagogical Education, Donetsk (Donetsk People's Republic)

Abstract. The article deals with the current pedagogical approaches to the components, structure and description of analytical activity. Different models of analytical activity are reviewed: activity approach (E.V. Naznachilo, N.A. Zinchuk, V.V. Yagupov, N.P. Pichugova), systematic approach (L.P. Polovenko, O.N. Yarygin, and A.A. Korostelev), structuralactivity approach (L.M. Plakhova). Within each approach the main components and stages of the analytical activity are described. The emphasis is laid on the three-dimensional model of analytical practice of the school principal: the technology of the analysis of the results of educational system operation (A.A. Korostelev), the element of that is a heuristic algorithm of unmathematical character, consisting of five stages. This technology combined a motivational sense, target, technological levels. The structural components of the analytical activity of the school's head are highlighted and described: value-motivation (personality attitude of leader toward analytical activity, value of parties and her meaningfulness in administrative activity, necessity of personality to improve and develop in this type of activity), goal-oriented (intentional aspect), cognitive-operational (complex of knowledge, abilities, practical skills, necessary for realization of effective and effective analytical activity) and reflective (self-esteem, self-awareness, self-management, self-design their own analytical activities).

Keywords: analysis, practice, analytical practice, analytical practice of the principal, structure analysis program, the stages of analytical practice, activity approach, system approach.

\section{УДК 376.016: 51}

\section{ПОДГОТОВКА БУДУЩИХ УЧИТЕЛЕЙ К РАБОТЕ С ДЕТЬМИ, ИСПЫТЫВАЮЩИМИ ТРУДНОСТИ В ОСВОЕНИИ ОСНОВНЫХ ОБРАЗОВАТЕЛЬНЫХ ПРОГРАММ ОБЩЕГО ОБРАЗОВАНИЯ, РАЗВИТИИ И СОЦИАЛЬНОЙ АДАПТАЦИИ}

(C) 2016

И.К. Кондаурова, кандидат педагогических наук, доцент, заведующий кафедрой математики и методики ее преподавания Саратовский национальный исследовательский государственный университет, Саратов (Россия)

Аннотаџия. В статье предложен авторский подход к проектированию и реализации профессиональнометодической подготовки будущих учителей математики к работе с детьми, испытывающими трудности в освоении основных образовательных программ общего образования, развитии и социальной адаптации, в том числе с детьми с ограниченными возможностями здоровья, в контексте требований Национальной образовательной инициативы «Наша новая школа», Национальной стратегии действий в интересах детей на 2012-2017 годы, ряда других нормативных документов. Обозначены цели изучения, планируемые результаты и примерное содержание раздела «Методика обучения математике учащихся, испытывающих трудности в освоении основных образовательных программ общего образования, развитии и социальной адаптации, в том числе детей с ограниченными возможностями здоровья» дисциплины «Методика обучения математике детей с особыми образовательными потребностями». Структура содержания раздела представлена тремя модулями. Первый связан с изучением психологопедагогических аспектов и нормативно-документального обеспечения обучения, воспитания и развития учащихся, испытывающих трудности в освоении основных образовательных программ общего образования, развитии и социальной адаптации. Второй модуль включает в себя общие вопросы методики обучения математике учащихся, испытывающих трудности в освоении основных образовательных программ общего образования, развитии и социальной адаптации. В третьем модуле представлены частные вопросы методики обучения математике учащихся, испытывающих трудности в освоении основных образовательных программ общего образования, развитии и социальной адаптации. В заключение статьи приведены рекомендации по организации учебно-исследовательской деятельности будущих учителей математики в контексте изучаемого методического материала.

Ключевые слова: подготовка будущих учителей; дети, испытывающие трудности в освоении основных образовательных программ общего образования, развитии и социальной адаптации; дети с ограниченными возможностями здоровья.

Актуальность затронутой в статье темы обусловлена повышенным вниманием государства к детям с ограниченными возможностями здоровья, что нашло отражение в ряде нормативных документов: Национальной образовательной инициативе «Наша новая школа», Национальной стратегии действий в интересах детей на 2012-2017 годы, проекте Концепции Федерального государственного образовательного стандарта (ФГОС) для обучающихся с ограниченными возможностями здоровья (ОВ3).
В Национальной образовательной инициативе «Наша новая школа» (утверждена Президентом Российской Федерации 4 февраля 2010 года, Пр-271) сформулирован основной принцип инклюзивного образования: «Новая школа - это школа для всех. В любой школе будет обеспечиваться успешная социализация детей с ограниченными возможностями здоровья, детей-инвалидов, детей, оставшихся без попечения родителей, находящихся в трудной жизненной ситуации. ... В каждом образовательном учреждении должна быть 